Editorial

\title{
Superbugs: a challenge for scientific research
}

\section{Editorial}

It is my immense pleasure and honor to introduce you the Journal of Microbiology \& Experimentation (JMEN) of MedCrave Publishing Group. JMEN covers vast areas of research in Microbiology from industrial and economic to medical and environmental aiming this way to act as a forum for our common scientific passion: the study of the microorganisms.

There are indeed limitless topics of high interest in Microbiology, allow me however to open the discussion with one of the most important ones for public health worldwide: The emergence and spread of multi-drug-resistant pathogenic bacteria, colloquially referred to as the "superbugs".

Infections caused by multi-drug-resistant bacteria and especially carbapenem-resistant Enterobacteriaceae (CRE) are associated with thousands of deaths each year ${ }^{1}$ raising significantly the hospitalization costs in many countries such as the US, India, China, Greece and Israel. The problem is obviously multi-factorial and seems difficult to be addressed. Bacteria possess an extremely versatile genetic armamentarium, being able to acquire genes horizontally, mutate swiftly and accumulate the necessary mechanisms for their survival under evolutionary pressure. ${ }^{2}$ Humans however, seem to be much more responsible for the emergence of antibiotic resistance. Immoderate antibiotic prescription, uncontrolled public access to antibiotics in some countries and the use of sub therapeutic doses for the promotion of animal growth in the agricultural sector are only some of the main contributing factors. Moreover, the limited flow through the pipeline of novel antibiotics and the problems that big pharmaceutical companies are facing for the development, license and commercial use of these compounds are leading the less optimistic to talk about future apocalyptic scenarios.

This is where the role of biomedical research towards antibiotic resistance performed by universities, public institutions and hospitals
Volume I Issue I - 2014

\author{
Meletis Georgios \\ Department of Clinical Microbiology, St. Paul's General Hospital, \\ Greece \\ Correspondence: Meletis Georgios, Department of Clinical \\ Microbiology, St. Paul's General Hospital, Ethnikis Aminis \\ |61, 55 | 34, Thessaloniki, Greece, Tel 00306974282575, Fax \\ 00302310301340,Email meletisg@hotmail.com
}

Received: May 09, 2014 | Published: May 10, 2014

becomes critical more than ever before. The fields of action include but are not limited to surveillance and isolation reports, study of the microbial resistance mechanisms and pathogenesis, detection methodologies, treatment options and hopefully, development of new drugs against the superbugs.

\section{Acknowledgements}

None.

\section{Conflict of interest}

Author declares that there is no conflict of interest.

\section{References}

1. Centers for Disease Control and Prevention. Detect and protect against antibiotic resistance budget initiative. Threat Report, USA; 2013.

2. Meletis G, Vavatsi N, Exindari M, et al. Accumulation of carbapenem resistance mechanisms in VIM-2-producing Pseudomonas aeruginosa under selective pressure. Eur J Clin Microbiol Infect Dis. 2014;33(2):253-258. 